\title{
A Customer Centric Improved Cloud Service Model
}

\author{
Khaled Hamed Abdulla Bouba ${ }^{1}$, Prateek Singh ${ }^{2}$ \\ ${ }^{1}$ M. Tech. Computer Science \& Engineering, Department of Computer Science and IT, SHUATS University P.O Naini, Allahabad, U.P- \\ 211007, India
}

${ }^{2}$ Assistant Professor, Department ofComputer Science and IT, SHUATS University P.O Naini, Allahabad, U.P-211007, India

\begin{abstract}
Cloud computing is a new Internet-based computer technology. As a new concept, cloud computing has attracted the IT enterprise attention especially the e-commerce enterprise. At present, there are great problems of environmental costs during the application of e-commerce by the enterprises, but with the advent of cloud computing, all such problems can be shorted out. The paper puts forward that cloud computing has a wide perspective in the application of E-commerce by describing the conception and characteristic of cloud computing, and special analysis of the main aspect of improving E-commerce by cloud computing. Although Cloud Computing can bring lots of opportunities for e-commerce companies, there are still some issues that needs to be address before we move on to the "cloud". For examples, there is no unified Cloud standards yet which may cause trouble to use Cloud Computing; the quality of Cloud service cannot be guaranteed; migration effort should be considered, etc.
\end{abstract}

Keywords: Cloud Computing, Cloud Storage, Web Technology, IT Service

\section{Introduction}

Digital Marketing (also Online Marketing, Internet Marketing or Web Marketing) name for marketing activity carried out online, as opposed to traditional marketing through print media, live promotions, tv and radio advertisement.

The growth of Digital Marketing Industry is a direct consequence of the global phenomenon that is the Internet, and effectiveness of Digital Marketing channels in generating revenue and awareness. Compared to traditional methods of advertising, Digital Marketing offers rather realistic costs (particularly important for small- and medium-size businesses and start-ups), accurate targeting and excellent reporting.

Here I am imagine an ecommerce platform that allows customer service to have a single view of a customer across all channels, a centralized order and inventory management system that can efficiently fulfill orders from all your sales channels, including brick and mortar stores, or utilize a customer's order history data to provide personalized and relevant offers. The possibilities brought to light with the advent of a complete ecommerce platform for business optimization and improved efficiencies as well as deepened customer engagement and satisfaction are limited only by one's creativity.

\section{Problem Statement}

After sale, service is an important part of any bussiness. In general customers have to go on any particular physical location for the service but here $i$ am trying to create a system by which the user can use the service without visiting the physical location of the service centre.

\section{Existing Work}

Rachana C R (2016) In this paper, the author had concluded that the term cloud computing in no longer a buzz word, but indicates how corporate information and ecommerce applications are stored online, can be accessed and shared. Cloud computing offers many benefits to the ecommerce market. The speed of building ecommerce websites, the cost savings of infrastructure and the reliability of a stable platform are just a few examples of the benefits of a cloud service.

Nevin Aydin et al (2015) The popularity and the application areas of the cloud computing has significantly increased since it was proposed by Google in 2007. Cloud computing includes set of resources and services to be shared among users via Internet. As a result, internet computing is another name for the cloud computing. In the earlier years, the cloud computing was a theoretical concept, but now it can be applied within various industries. In this paper, the authors presented how the cloud computing has influenced ecommerce businesses from its inception till present date.

Brigitte Preissl (2014) The empirical data presented here have been derived from a company survey which has been conducted in eight service sectors across the EU. From these eight sectors four sectors have been chosen for the present analysis. The criterion for selection was comparability with respect to market orientation, regulation intensity and performance indicators.

\section{Proposed System}

E-Business enables an enterprise to spread its wings to the global customer. To extend the sales platform to a futuristic dimension, business houses have incorporated software that can run on platforms offered by the World Wide Web.

In my dissertation work any person who wants to use the cloud service can register with the application. User registration is a simple process. After registration any one can login and can send their requirement regarding software development.

The organization can see the request of all the clients and could accept or reject. The organization decide the financial details and the revert it to customer and after approval of the customer the process could be start. 


\section{International Journal of Science and Research (IJSR) \\ ISSN (Online): 2319-7064}

Index Copernicus Value (2015): 78.96 | Impact Factor (2015): 6.391

Here I am imagine an ecommerce platform that allows customer service to have a single view of a customer across all channels, a centralized order and inventory management system that can efficiently fulfill orders from all your sales channels, including brick and mortar stores, or utilize a customer's order history data to provide personalized and relevant offers. The possibilities brought to light with the advent of a complete ecommerce platform for business optimization and improved efficiencies as well as deepened customer engagement and satisfaction are limited only by one's creativity.

\section{A. Material and Methods \\ Cloud computing is the delivery of computing services over the Internet. Cloud services allow individuals and businesses to use software and hardware that are managed by third parties at remote locations. Examples of cloud services include online file storage, social networking sites, webmail, and online business applications. The cloud computing model allows access to information and computer resources from anywhere that a network connection is available. Cloud computing provides a shared pool of resources, including data storage space, networks, computer processing power, and specialized corporate and user applications.}

\section{Module Description:}

Following modules are developed in to my application.

- Inventory Module

- Assistance Module

- Asset Management

Inventory Module - This module is intended for component management of the computing hardware. We can keep record of following-

- Computers, monitors, printers and phones

- Software

- Hardware

- Network devices (IP, MAC, VLANs)

- Consumable and cartridges with alerts

- External devices (scanners, graphic tablets)

Assistance Module - In this module we can generate the tickets and we can send the help desk against the particular ticket.

Asset Management Module- In asset management module we perform the following operations-

- Modifications tracking and history

- Asset localisation by geographic area, room, service department, etc.

- Financial information: warranty, contracts, suppliers, etc.

- Equipment lifecycle

- Advanced multi-criteria search function

- Alerts, reporting and dashboards

- Companies (manufacturers, suppliers, others...) and associated contacts

- Contracts (loan, hiring, leasing, insurance, maintenance and service)

- Documents related to the inventoried elements, contracts, types of authorised documents

- Budget management

\section{Results and Discussion}

We have focus in all the respect as per the mention in above figure. The most important feature of our application is providing service to our clients. It could be depicted like the following-

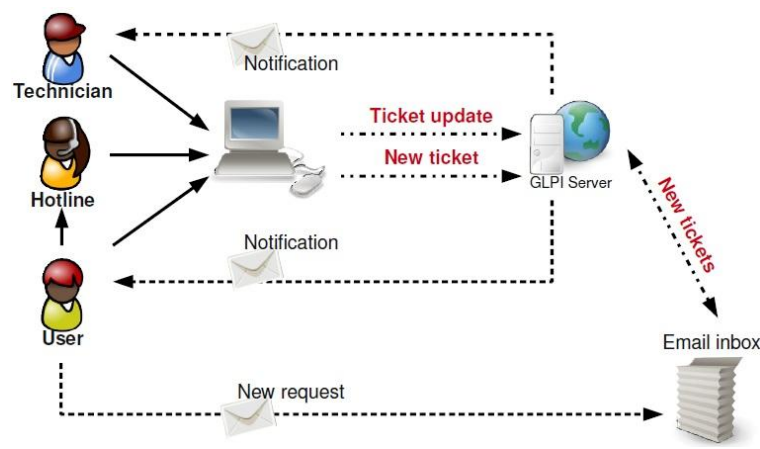

The New Ticket allotment is the most important feature of our work \& it could be depicted like the following-

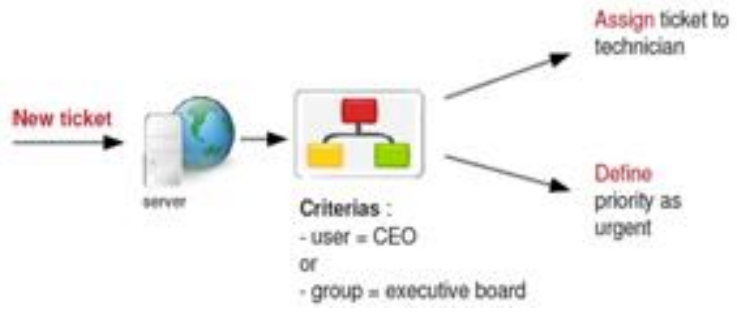

\section{Conclusion}

This thesis works on Information Resource-Manager with an additional Administration- Interface. You can use it to build up a database with an inventory for your company (computer, software, printers...). Our system will make administrator life easy and he/she could track the status of the customer service or items in an efficient way.

The principal functionalities of the application are :

1) We can manage the customer service related data into our system.

2) We can also maintain the available stock report.

\section{Future Scope}

Small towns and villages which are away from indulgences like malls and brand stores get access to wide variety of products thanks to e-commerce sites. I think these small towns and villages will benefit the most from e-commerce and they will also be a major factor in driving the growth of e-commerce in India. Though the current share of ecommerce is very little in the total pie, it is going to get bigger and bigger as the years pass.

Though the market currently looks over-crowded, there is always a scope for new entrants, provided they offer some value to the market. I think as the sector is new, players who enter the sector with a long term plan should be able to do better. 


\section{References}

[1] Fabian Aulkemeier, Milan Schramm, A Service-Oriented E-Commerce Reference Architecture, Journal of Theoretical and Applied Electronic Commerce Research, ISSN 0718-1876 Electronic Version, VOL 11 / ISSUE 1 / JANUARY 2016 / 26-45

[2] Indrajit Das, Ria Das, Cloud-e commerce: Synthetic platform for ecommerce transactions and services, International Journal of Latest Trends in Engineering and Technology (IJLTET) Vol. 3, Vol. 3 Issue 1 September 2013

[3] Brigitte Preissl, E-business in Service Industries: Usage patterns and service gaps, German Institute for Economic Research, DIW

[4] Danping Wang, Influences of Cloud Computing on ECommerce Businesses and Industry, Journal of Software Engineering and Applications, 2013, 6, 313-318

[5] Mario Bravetti, Roberto Lucchi, Gianluigi Zavattaro, Roberto Gorrieri, Web Services for Ecommerce: guaranteeing security access and quality of service, Department of Computer Science University of Bologna Mura Anteo Zamboni, 740127 Bologna Italy

[6] AzubuikeEzenwoke, Sanjay Misra, Mathew Adigun, An Approach for e-Commerce On-Demand Service-oriented Product line Development, ActaPolytechnicaHungarica, Vol. 10, No. 2, 2013

[7] Shen Juncai and Qian Shao, Based on Cloud Computing E-commerce Models and Its Security, International Journal of e-Education, e-Business, e-Management and e-Learning, Vol. 1, No. 2, June, 2011

[8] KawserWazedNafi, TonnyShekhaKar, Md. Amjad Hossain, M. M. A. Hashem, A New Trusted and Secured E-commerce Architeture for Cloud Computing, Khulna University of Engineering and Technology Khulna, Bangladesh

[9] Nevin Aydin, Cloud Computing for E-Commerce, IOSR Journal of Mobile Computing \& Application (IOSRJMCA) e-ISSN: 2394-0050, P-ISSN: 2394-0042.Volume 2, Issue 1. (Mar. - Apr. 2015), PP 27-31 